\title{
Combined degeneration of the spinal cord due to deficiency of alimentary vitamin $\mathrm{B}_{12}$
}

\author{
A. VERJAAL AND A. H. C. C. TIMMERMANS-VAN DEN BOS \\ From 'S. Gravenhage, The Netherlands
}

Deficiency of vitamin $\mathbf{B}_{\mathbf{1 2}}$ may result in two typical syndromes, anaemia and combined degeneration of the spinal cord. Vitamin $\mathbf{B}_{12}$ deficiency generally results from interstitial gastritis in which intrinsic factor, required for the absorption of vitamin $B_{12}$, is lacking and when it is caused by inadequate or insufficient nutrition macrocytic anaemia is often present but the deficiency seldom assumes such a serious form as combined degeneration of the spinal cord. Indeed we were unable to find in the literature a single well-documented case of combined degeneration of the cord due to alimentary vitamin $B_{12}$ deficiency. The publication of a case which has been investigated both clinically and anatomically therefore appears to be warranted.

\section{CASE REPORT}

Mrs. G., 68 years old, daughter of a Javanese mother and a Dutch father, was admitted to the municipal hospital in a deplorable condition on 24 November 1964. She weighed $43.3 \mathrm{~kg}$. There was decubitus of the sacral region and her psychic condition was characterized by apathy and paranoid withdrawal. There was probably a considerable dementia but no clear impression on this point could be obtained because of the difficult contact with the patient.

The patient had attended a junior secondary school in Indonesia and had afterwards been employed in the Education Department at Batavia. She married at the age of 20 and six children were born from this marriage. In 1946 she had a psychotic condition for a period of three weeks, for which she was successfully treated with electroshock. In the same period she joined the Seventh Day Adventists and became a vegetarian. In 1955 her marriage was dissolved and she left for the Netherlands. Since then she had lived alone in one room and prepared her own food, consisting of bread, nuts, sometimes vegetables, and a little fruit. An exact dietary history could not be obtained. In the course of 1961 walking gradually became difficult and her general physical and mental condition declined, till finally she became entirely bedridden.

On admission physical examination revealed no abnormalities. The neurological examination showed a paraplegia in flexion. The arm reflexes were brisk with a Hoffmann-Trömner reflex on both hands. The knee and ankle jerks were absent. The Babinski sign was of the extensor type bilaterally. The abdominal reflexes were absent. There was a severe disturbance of deep sensibility and a slight disturbance of pain sensibility below the level of the umbilicus. Moreover there was urinary retention of $1900 \mathrm{ml}$. Lumbar puncture showed clear fluid under normal pressure with $57 \mathrm{mg} . / 100 \mathrm{ml}$. protein and 12 lymphocytes per c.mm. The colloidal curves were normal.

Radiological examination of the skull and the vertebral column showed no abnormalities. The E.E.G. pattern was normal.

Since the neurological picture was characteristic of combined degeneration of the spinal cord due to vitamin $B_{12}$ deficiency, special tests were done for pernicious anaemia. Gastric acid values were normal: fasting 8-16 and after $100 \mathrm{ml}$. of tea, successively $42-70$, 48-67, 16-46 mEq. Hcl. per litre. The haemoglobin content of the blood was $12.5 \mathrm{~g} . / 100 \mathrm{ml}$. with 3 million erythrocytes per c.mm. There was a megalocytosis and a macrocytosis with an erythrocyte diameter of 7.5 to

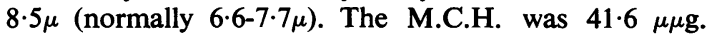
(normal value 27-32 $\mu \mu \mathrm{g}$.), the M.C.V. $137 \mathrm{c} \mu$ (normal. value $82-96 \mathrm{c} \mu$ ). The serum iron content was $22 \mu \mathrm{g}$./ $100 \mathrm{ml}$. and the total iron-combining capacity $243 \mu \mathrm{g}$./ $100 \mathrm{ml}$. Leucocytes numbered 6,600 per c.mm. (stabs 2 , segments 77 , eosinophils 2 , lymphocytes 10 , monocytes $9 \%$ ). There was pronounced hypersegmentation.

Liver function tests were normal and so was the albumin spectrum of the serum. The creatinine content of the serum amounted to $6.9 \mathrm{mg}$./l. Examination of the faeces for digestive disturbances showed no abnormalities.

The bone marrow of the sternum showed active erythropoiesis with some megaloblasts. Granulopoiesis showed many giant band forms and giant myelocytes. The bone marrow was described by the haematologist as 'in keeping with $B_{12}$ deficiency'. The vitamin $B_{12}$ content of the serum was $20 \mu \mu \mathrm{g}$. per ml. determined by the method of Spray (1900) whereby the growth of Lactobacillus leichmanni serves as a parameter. The folic acid content of the serum was normal (12.4 mug. per ml.) determined by the growth effect on Lactobacillus casei (normally more than $4 \mathrm{~m} \mu \mathrm{g}$. per $\mathrm{ml}$.).

Because of the extremely low vitamin $B_{12}$ content of the blood serum, the macrocytic anaemia, the combined degeneration of the spinal cord, the normal gastric acid values and the normal food digestion, alimentary vitamin $\mathbf{B}_{\mathbf{1 2}}$ deficiency was diagnosed. The patient was then treated 


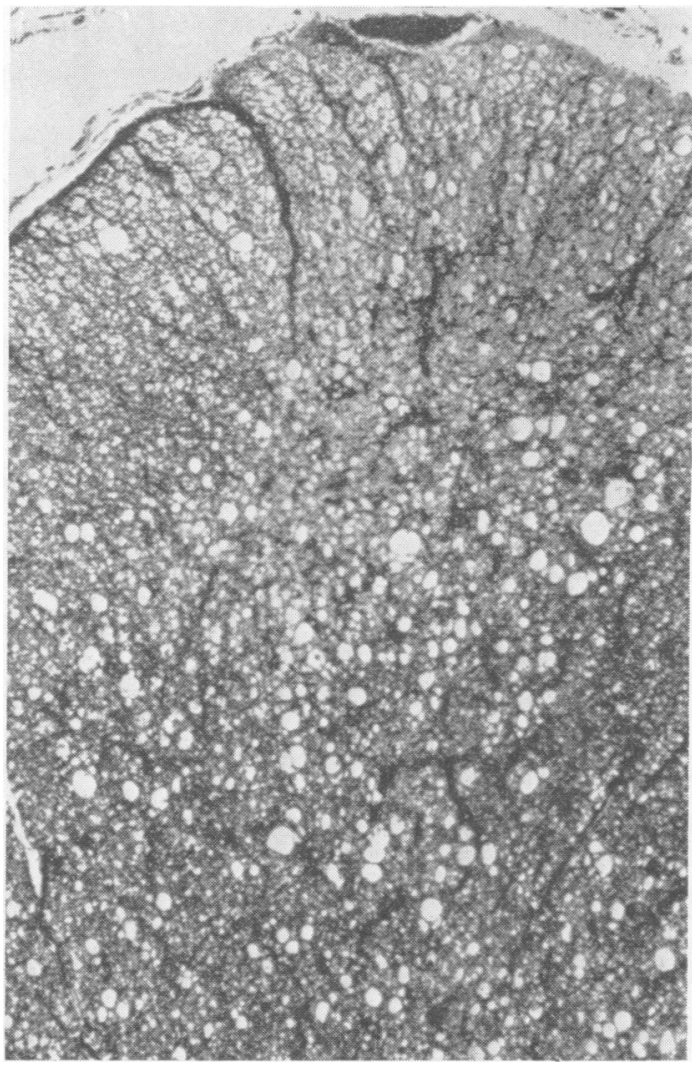

FIG. 1. Demyelinization of the lateral pyramidal tract and the spinocerebellar tracts. Level C.5. Weigert-Pal. $\times 300$.

with vitamin $B_{12}$ parenterally, 1,000 micrograms three times a week. There was no improvement in her general condition nor in her neurological state. The patient had a number of serious complicating infections of the urinary tract, the intestine, the skin, and the lungs which demanded repeated treatment with large doses of various antibiotics. In the end decubitus could no longer be arrested and she died on 11 April 1965 in a cachectic condition.

\section{POST-MORTEM EXAMINATION}

The post-mortem examination showed fatty degeneration of the liver with central lobular necrosis, lung fibrosis on both sides, superficial defects of the gastric mucosa, acute cystitis and pyelitis on the right with gravel in the renal pelvis and ureter.

The spinal cord, brain, one sacral nerve, one tibial nerve, and a posterior tibial muscle were fixed in formalin and examined by Dr. J. Bethlem, who reported as follows:

Sectioning of the brain reveals nothing of interest. Sectioning of the cord shows a grey discoloration in the region of the posterior columns in all cervical and thoracic segments.

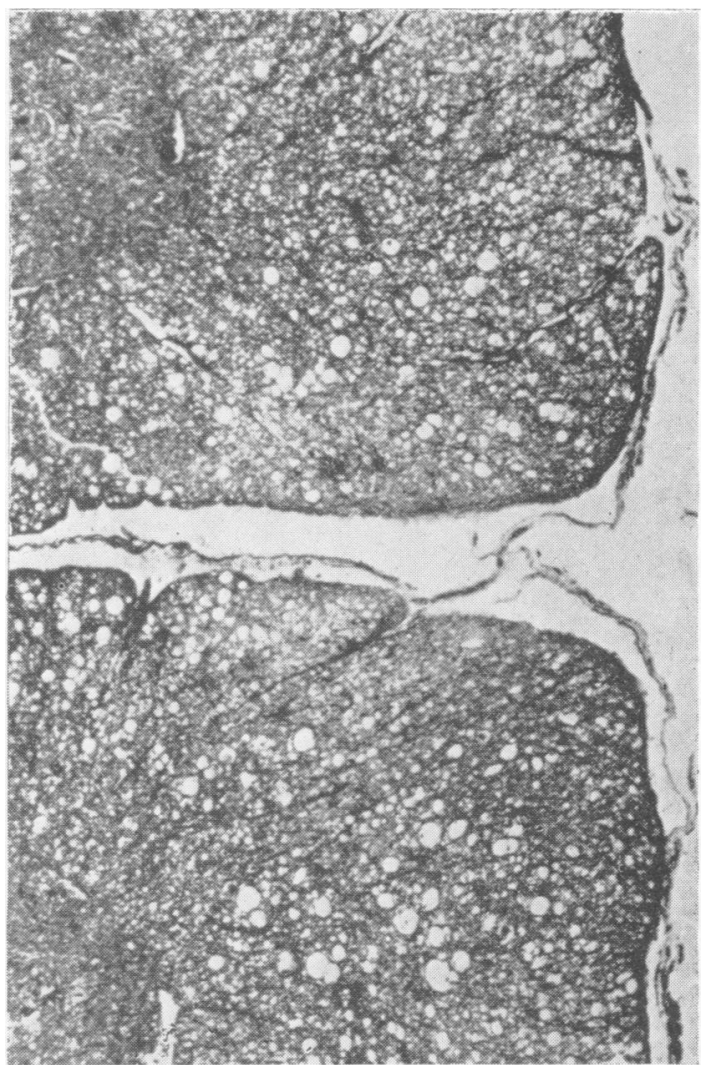

FIG. 2. Demyelinization of the anterior pyramidal tract, vacuolization, and destruction of axis cylinders. Level C.5. Weigert-Pal. $\times 300$.

MICROSCOPY The mid-thoracic cord segments show demyelinization in large areas of the white substance, the parts around the grey substance being the least affected.

In the posterior columns the region of the fasciculus cuneatus is particularly affected. In the lateral columns the pyramidal tracts, the spinocerebellar tracts, and the anterior pyramidal tracts are affected on both sides. Rostrally the intensity of the process decreases. The degeneration can be traced, however, in the high cervical levels. Caudally the lateral pyramidal tracts are affected in the lumbar cord but no degeneration is to be seen in the sacral region. In the affected areas of the cord, the myelin sheaths are greatly swollen, which has led to vacuolization of the white matter. Numerous fat-laden Sudan-positive phagocytes are observed. The axis cylinders are largely destroyed. There is no astrocytic reaction.

Some roots of the cauda equina show swelling of the myelin sheaths; the roots of the spinal cord are intact. The intervertebral ganglia show no abnormalities.

The tibial nerve shows intense demyelinization with numerous phagocytes laden with Sudan-positive material 


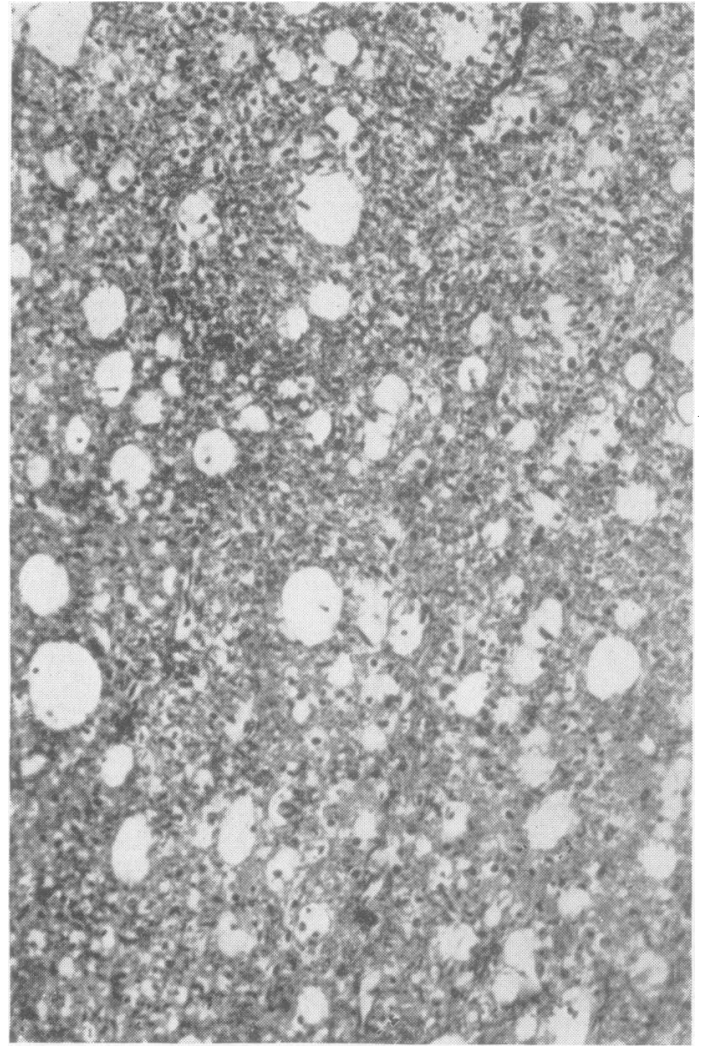

FIG. 3. Demyelinization in the fasciculus cuneatus of the posterior column. The myelin sheaths are swollen which has led to vacuolization; fat-laden phagocytes; destruction of axis cylinders. T.8. Weigert-Pal. $\times 300$.

and moderate proliferation of the Schwann cells. Sometimes there is a fusiform swelling of the axis cylinders but otherwise the axis cylinders are relatively unaffected. The sacral nerve shows local sudanophil destruction of the myelin sheaths, though to a lesser extent than in the tibial nerve.

In the brain nothing of interest is observed, in particular no foci of demyelinization in the white matter. The corpora mamillaria are intact.

In the anterior tibialis muscle a very pronounced atrophy of all fibres is to be seen. There are few structural changes. Targetoid fibres are present here and there but no target fibres are seen with certainty. There is a great increase of small hyperchromatic sarcolemmal nuclei. The endomysial fat and the connective tissue are also increased. Partly organized, partly recanalized thrombi are seen in some medium-sized arteries.

A few intramuscular nerve branches show distinct loss of myelin sheaths and axis cylinders with an increase of the endoneural connective tissue. There are no signs of inflammation.

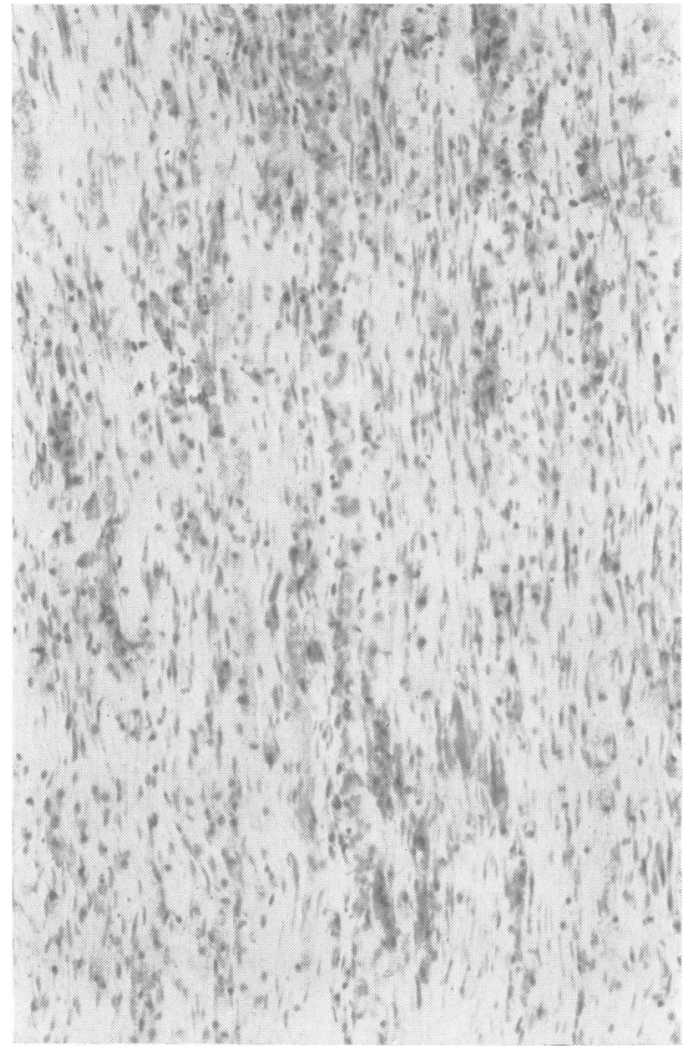

FIG. 4. Tibial nerve. Demyelinization, moderate proliferation of Schwann cells phagocytes with Sudan-positive material. Fusiform swelling of axis cylinders. Sudan III. $\times 300$.

The histological picture is entirely compatible with combined degeneration of the spinal cord and neuropathy as a result of vitamin $B_{12}$ deficiency.

\section{DISCUSSION}

The normal vitamin $\mathbf{B}_{12}$ content of the blood serum, according to the table given by Herbert (1959) in his study on megaloblastic anaemias, varies from about 100 to $1,000 \mu \mu \mathrm{g}$. per $\mathrm{ml}$. A vitamin $\mathbf{B}_{12}$ level below $100 \mu \mu \mathrm{g}$. per ml. may result in macrocytic anaemia but combined degeneration of the spinal cord as a rule occurs only with values below $50 \mu \mu \mathrm{g}$. per ml.

Vitamin $B_{12}$ deficiency due to inadequate nutrition commonly causes macrocytic anaemia but seldom to such a degree that combined degeneration of the cord results. In the literature attention is frequently drawn to a single case which Badenoch mentioned 
casually in 1954. It concerned a 15-year-old vegetarian, but no neurological examination and no vitamin $B_{12}$ studies are reported. Badenoch only states that this boy presented the typical picture of combined degeneration of the cord "which responded dramatically to treatment with vitamin $\mathbf{B}_{12}$ alone'. Wokes, Badenoch, and Sinclair (1955), who studied alimentary vitamin $\mathbf{B}_{\mathbf{1 2}}$ deficiency in vegetarians, state: 'nervous symptoms were common among the vegans, but have not been plotted, because their subjective nature makes their precise rate of development difficult to determine'. Grant, Hoffbrand, and Wells (1965) described a vegetarian with free gastric acid and normal vitamin $\mathrm{B}_{12}$ absorption. The vitamin $B_{12}$ content of the serum was $90 \mu \mu \mathrm{g}$. per $\mathrm{ml}$. In the course of two years this man developed a myelopathy at the T8 level with severe spastic paraplegia and loss of all sensory modalities below T8. After laminectomy had failed to reveal a spaceoccupying lesion, $1,000 \mathrm{~g}$. vitamin $\mathbf{B}_{12}$ was injected intramuscularly every day, which, however, did not influence the neurological syndrome. The authors state: 'the relative high serum $B_{12}$ level indicates that his $\mathrm{B}_{12}$ deficiency and the spinal cord disease were probably unrelated.' Smith (1962), who examined a series of 12 vegans, says in passing: 'apart from two vegans with subacute combined degeneration of the cord, there were no abnormal signs of definite significance to be elicited in this series.' Of these two patients too, no neurological examination is reported and no vitamin $\mathbf{B}_{12}$ content of the blood serum.

The woman we had the opportunity of observing both clinically and anatomically fulfilled the essential requirements to warrant a diagnosis of combined degeneration of the cord due to nutritional vitamin $B_{12}$ deficiency. She was on a strict vegetarian regimen for 20 years; gastric acid values were normal, food digestion was unimpaired, there was a macrocytic anaemia, and the vitamin $B_{12}$ level of the blood serum was as low as $20 \mu \mu \mathrm{g}$. per $\mathrm{ml}$. The neurological syndrome she presented was characteristic of combined degeneration of the spinal cord, and this clinical diagnosis was confirmed at necropsy.

\section{REFERENCES}

Badenoch, J. (1954). The use of labelled vitamin $B_{12}$ and gastric biopsy in the investigation of anaemia. Proc. roy. Soc. Med., 47, 426-427.

Grant, H. C., Hoffbrand, A. V., and Wells, D. G. (1965). Folate deficiency and neurological disease. Lancet, 2, 763-767.

Herbert, V. (1959) The Megaloblastic Anemias. (Modern medical monographs.) Grune and Stratton.

Smith, A. D. M. (1962). Veganism: a clinical survey with observations on vitamin $B_{12}$ metabolism. Brit. med. J., 1, 1655-1658.

Spray, G. H. (1955). An improved method for the rapid estimation of vitamin $B_{1,}$ in serum. Clin. Sci., 14, 661.

Wukes, F., Badenoch, J., and Sinclair, H. M. (1955). Human dietary deficiency of vitamin $B_{12}$. Voeding, 16, 590-602. 